\title{
SOBRE O “NOVO E SEM PRECEDENTES” NO CAMPO DA POLÍTICA
}

\author{
ABOUT THE “NEW AND UNPRECEDENTED” IN THE FIELD OF POLITICS
}

José João Neves Barbosa Vicente*

\section{RESUMO}

A proposta do artigo é apresentar a postura de Arendt diante do fenômeno totalitário, um acontecimento para ela inédito e sem precedentes na história da humanidade. $\mathrm{O}$ artigo discute e ressalta também o método utilizado por ela não apenas para compreender e denunciar o referido fenômeno, mas sim para lidar com todos os eventos que destroem os conceitos e categorias tradicionais comumente utilizados no processo de compreensão.

PALAVRAS-CHAVE: Causalidade. Compreender. Política. Totalitarismo.

\begin{abstract}
The aim of this article is to present the stance of Arendt on the totalitarian phenomenon, an event for her unprecedented and unparalleled in the history of mankind. On the other hand, this article discusses noting also the method used for her not only to understand and expose this phenomenon, but rather to deal with all the events that destroy the concepts and traditional categories commonly used in the process of understanding.
\end{abstract}

KEYWORDS: Causality. Understand. Politics. Totalitarianism.

\section{INTRODUÇÃO}

Qualquer estudo sobre o pensamento de Arendt deve levar em consideração a sua paixão pela compreensão, principalmente a compreensão do fenômeno totalitário. Afinal, para ela, se a sua geração foi obrigada a viver a maior parte da sua vida adulta sob as garras do terror praticado pelos regimes totalitários, agora é o momento de se fazer um esforço sem precedentes para que seja possível encontrar respostas, não apenas para o que aconteceu, mas também porque aconteceu e como foi possível tal acontecimento. Para ela, portanto, quando

\footnotetext{
* Mestre em Filosofia pela Universidade Federal de Goiás (UFG), Doutorando em Filosofia na Universidade Federal da Bahia (UFBA) e professor de Filosofia da Universidade Federal do Recôncavo da Bahia (UFRB). Email: josebvicente@bol.com.br.
} 
se trata do fenômeno totalitário, a questão mais importante não se reduz ao rir ou chorar, mas principalmente ao compreender.

Ela demonstra em sua obra, de forma clara, o gosto pela reflexão a partir de fatos e situações concretos, ela demonstra a coragem para encarar de frente a realidade, por mais terrível que seja, e demonstrar, conforme pensava Jaspers, que enquanto houver seres com capacidade crítica, tanto a garra exterminadora da força totalitária, como qualquer outro tipo de mal encontrarão resistência. A coragem de Arendt pode ser considerada como a mais antiga das virtudes políticas, a primeira das qualidades humanas, pois é aquela que garante todas as outras. Trata-se de uma coragem presente na mera disposição de agir e falar, de inserir-se no mundo, de sair do abrigo particular para se expor aos outros e, com eles, estar pronto para arriscar a revelação; uma coragem, portanto, que, necessariamente, nada tem a ver com a atividade de quem coloca a própria vida em risco. Arendt, como destacou Roviello (1990, p. 89), nunca fugiu à tarefa de compreender. Na verdade, todas as suas análises referentes aos "acontecimentos que marcaram o nosso mundo moderno", foram desenvolvidas tendo em vista a sua paixão pela compreensão. Ela sempre procurou "apreender a 'verdade interna' do acontecimento".

Em outros termos, para Arendt, nenhum acontecimento é capaz de colocar em dúvida a capacidade humana de compreender. Para Ela, a paixão pela compreensão, como observou Young-Bruehl (1997, p. 126), "pressupõe um processo profundo de têmpora, o tipo de processo que, afirmava Nietzsche, ou mata ou fortalece". A luta pela compreensão, principalmente pela compreensão do fenômeno totalitário, tornou-se primordial para Arendt, ela não podia viver sem tentar compreende-lo. E como aluna de Heidegger, aprendeu com o mestre, que todo o grande pensador passa a vida pensando um único pensamento, assim o pensamento de Arendt, em termos gerais, é fundamentalmente dirigido na tentativa de decifrar, compreender os massacres administrativos do século XX provocados pelos regimes totalitários. A questão é descobrir como foi possível, no interior da cultura ocidental, aparecer o tipo da realidade tal como o totalitarismo e qual o antídoto para isso.

Em sua tarefa de compreender, Arendt teve, no entanto, uma grande surpresa: descobriu que não podia contar com a ajuda da tradição de pensamento nesse empreendimento. Não podia contar com os conceitos e categorias da nossa tradição definidas e redefinidas por mais de dois mil anos. Toda a "sabedoria do passado", diz Arendt (1993, p. 41), “morre em nossas mãos tão logo tentamos aplicá-la de forma honesta às experiências políticas centrais dos nossos tempos". O que significa dizer que "tudo o que sabemos sobre o 
totalitarismo indica uma terrível originalidade, que nenhum paralelo histórico é capaz de atenuar”. Só restava a ela fazer um caminhar solitário, isto é, sem a companhia e o apoio da nossa tradição do pensamento ocidental, o que significa dizer que ela teve que proceder na busca da compreensão sem se sustentar plenamente nas categorias teóricas do passado. Ela precisou, portanto, descobrir um novo método para lidar com os acontecimentos políticos da modernidade, um método, como sublinhou Duarte (2000, p. 122-127), destituído de "amparos" firmes e inquestionáveis, um método metaforicamente denominado de "pensamento sem corrimãos".

\section{I}

Escrita com o objetivo de compreender o que havia acontecido, Origens do totalitarismo não só apresentou ao mundo uma forma de dominação nova e sem precedentes na história da humanidade, mas também trouxe para discussão um método novo, a saber, uma forma nova de se lidar com os acontecimentos políticos que destroem os usos convencionais da investigação acadêmica; um método que mistura ao mesmo tempo, a curiosidade da história, a preocupação do documento e do arquivo, mas também a interrogação filosófica e o fervor ético. Todavia, trata-se, também, de um método que não dispensa a imaginação original, ainda que provoque em alguns leitores certos distúrbios, levando a distorção das análises de Arendt. W. Gurian, E. Voeglin e D. Riesman, por exemplo, viram na disposição interna da obra da autora: Antissemitismo, Imperialismo e Totalitarismo, uma espécie de determinismo onde o totalitarismo seria inevitável. Outra observação quanto a nós pouco interessante pelo fato de não contribuir em nada para a compreensão do pensamento político de Arendt, é a de I. Berlin atacando os fatos. Ou seja, para ele, as observações da nossa autora sobre o nazismo estão corretas, porém não trouxe nada de novo; quanto ao comunismo russo, diz ele, ela simplesmente se enganou. Ou seja, para I. Berlin, Arendt não disse, ou não mencionou um único fato sobre a Rússia que esteja correto. Essa observação de Berlin, no entanto, é contestada pelas provas históricas acumuladas e pelos documentos publicados desde 1951, todos esses materiais tenderam a confirmar a precisão da obra de Arendt e os julgamentos categóricos que ela efetuou.

Percebe-se, portanto, o motivo pelo qual é importante uma análise e apresentação do método arendtiano referente à compreensão do fenômeno totalitário quando se pretende estudar o seu pensamento. Qualquer tentativa de compreender Origens do totalitarismo, 
tomando a palavra Origens como se a obra fosse, por exemplo, um estudo genético de $A$ origem das espécies de Darwin, certamente será um fracasso. Uma postura desse tipo diante da obra de Arendt significa ir contra o seu método, pois seria acreditar que a autora apenas reconstrói os fatos, quando na verdade ela pensa, reflete. É claro que ela não pensa os universais, o puro invisível, mas os acontecimentos, em especial os acontecimentos políticos catastróficos da humanidade. Portanto, sua obra, em hipótese alguma, pode ser considerada como uma sequência causal evolutiva, cujo apogeu seria o totalitarismo. Na verdade, para Arendt, não existe nenhuma ação humana capaz de ser explicada inteiramente à luz do que aconteceu antes, e o fenômeno totalitário deve ser considerado um acontecimento sem precedentes e impossível de ser captado por qualquer evolução histórica. A autora, portanto, não faz uma revelação gradual da essência do totalitarismo porque essa essência simplesmente não existe antes de ter vindo a ser; o fenômeno totalitário é único e nenhum dos elementos, seja da Idade Média ou do século XVIII, podem ser qualificados de "totalitários".

Essa postura de Arendt, no entanto, não quer dizer opor-se à explicação causal a incapacidade do homem para compreender o seu passado e para agir sobre a sua história futura, nem negar a legitimidade de tal explicação, mas significa uma severa crítica à primazia e mesmo à exclusividade que lhe é demasiadas vezes concedida pela historiografia moderna. A "causalidade" e o "contexto" de um acontecimento para os antigos, diz Arendt (1972, p. 96), "eram vistos sob uma luz fornecida pelo próprio evento, iluminando um seguimento específico dos problemas humanos"; ou seja, eles nunca foram "considerados como possuidores de uma existência independente de que o evento seria apenas a expressão mais ou menos acidental, conquanto adequado". Isso significa dizer que, para os antigos, "tudo que era dado ou acontecia mantinha sua cota de sentido 'geral' dentro dos confins de sua forma individual e aí a revelava, não necessitando de um processo envolvente e engolfante para se tornar significativa". Arendt, portanto, não simpatiza com nenhuma forma de explicação que vê os acontecimentos como dependentes de grandes causas primeiras ligadas umas às outras por uma cadeia fatal, eliminando os homens da história dos gêneros humanos.

Em Arendt, se queremos falar de "causalidade", ela deve ser pensada de modo $a$ posteriori. Nesse sentido, em termos gerais, só podemos inteirar-nos do sentido de um acontecimento interrogando o próprio acontecimento, pois como observou Roviello (1990, p. 92), se reduzimos um acontecimento a mero efeito de uma causa, simplesmente "passaremos ao lado do essencial, do que Arendt designa por cristalização: o encontro entre diferentes elementos preexistente, imprevisível porque impossível de deduzir a partir desses elementos". 
Para Arendt (1993, p. 50), portanto, aqueles que insistem em explicar um evento "dentro de um quadro de categorias preconcebidas, sendo a mais grosseira delas a da causalidade", certamente jamais conseguirão compreender os acontecimentos como "algo irrevogavelmente novo". Para Arendt (1993, p. 49), se um acontecimento é capaz de iluminar o seu "próprio passado", ele "jamais pode ser deduzido dele". Para a nossa autora, portanto, a questão deve ser compreendida assim: o passado só advém com o acontecimento; é o acontecimento que estabelece suas origens como tais. O totalitarismo provocou uma verdadeira falência dos conceitos, das verdades e doutrinas da nossa tradição de pensamento.

A "tradição uma vez perdida" ou falida, como sublinhou Friedrich (1974, p. 119), "não pode ser restaurada", e como tal já não ajuda. Mas, para Arendt, não se pode fugir ou refugiar-se, por exemplo, em um mundo que seria o oposto moral do totalitarismo, como a religião ou a consciência. Aquele que conclui "dos terríveis acontecimentos de nossa época que temos de voltar à fé e à religião por razões políticas", diz Arendt (2008, p. 423), "mostra, a meu ver, a mesma descrença em Deus de seus adversários". Para ela, o que deve fazer é pensar de novo, ou em outros termos, pensar o mundo novamente para torná-lo de novo compreensível, o que em essência significa torná-lo novamente um lugar habitável. Não importa se não temos mais "os metros" para medirmos e "as regras sob as quais podemos subsumir o particular". O importante é sabermos que a nossa característica fundamental, diz Arendt (1993, p. 53), consiste em sermos "um ser cuja essência é o começo", o que significa dizer que cada um de nós possui "dentro de si um teor suficiente de origem para compreender sem categorias preconcebidas e julgar sem este conjunto de regras comuns que é a moralidade". Apenas desse modo o homem é capaz de "aprender a lidar com o que irrevogavelmente passou e reconciliar-se com o que inevitavelmente existe". Portanto, para Arendt, a única forma de reconciliarmo-nos com o mundo é tentar compreender o que passou, não adianta tentar domesticá-lo e nem esquecê-lo, mas procurar iluminá-lo com a compreensão, ainda que ele seja doloroso e vergonhoso, como foi o caso dos regimes totalitários.

\section{II}

Na presença de algo inédito o homem deve sempre recorrer a ele mesmo, ou seja, ele deve procurar em si próprio alguma faculdade capaz de propor critérios novos e evidenciar a novidade em questão. Essa faculdade, em termos arendtianos, é a faculdade de julgar. Ela 
“não tem parâmetro, não pode recorrer a coisa alguma senão à própria evidência do julgado". Esse julgar, em termos gerais, como nos diz Arendt (1999, p. 31-32), "não possui nenhum outro pressuposto que não a capacidade humana do discernimento, e tem muito mais a ver com a capacidade de diferenciar do que com a capacidade de ordenar e subordinar". Essa capacidade de julgar não pode significar outra coisa senão uma forma de tomar uma posição diante dos eventos particulares do mundo, refletir sobre eles sem que se disponha de antemão de um conceito ou regras universais que possam ser aplicados ao caso. Nesse sentido, tentar compreender o fenômeno totalitário significa para Arendt, fundamentalmente emitir "juízos" sobre fatos, mesmo que neles se não tivesse participado.

Compreender é uma forma de se lidar com a realidade humana. Ela não é uma "informação correta" e nem um "conhecimento científico", a compreensão como é entendida por Arendt (1993, p. 39), "é um processo complexo, que jamais produz resultado inequívoco". Ela é essencialmente uma forma de "atividade interminável" através da qual, "em constante mudança e variação, aprendemos a lidar com nossa realidade, reconciliamo-nos com ela, isto é, tentamos nos inserir em casa no mundo". Compreender vai muito além do simples relacionar os acontecimentos com determinadas leis gerais, compará-los com outros fatos análogos do passado. No caso do totalitarismo, por exemplo, como nos lembra Arendt, se agirmos apenas dessa forma, certamente estaremos passando ao lado daquilo que nele é o essencial, a saber, o seu caráter chocante e monstruoso. Compreender, portanto, pressupõe acima de tudo, uma certa dose de coragem e resistência para enfrentar a realidade nua e crua. Ela não significa em hipótese alguma, "negar nos fatos o chocante, eliminar deles o inaudito, ou ao explicar fenômeno, utilizar-se de analogias e generalidades que diminuam o impacto da realidade e o choque da experiência", compreender, diz Arendt (1990, p. 21) "significa, em suma, encarar a realidade sem preconceitos e com atenção, e resistir a ela - qualquer que seja, venha a ser ou possa ter sido".

Para se colocar na condição de julgar, de compreender algo inédito e sem precedentes, ou seja, o fenômeno totalitário, Arendt (1973, p. 15) recorreu a uma "instância da mente", segundo ela, de extrema importância, a saber, a imaginação. Distinta do sonho e da fantasia, a imaginação possibilita ao homem "remover-se mentalmente de onde" se encontra "fisicamente colocado", para pensar "que as coisas poderiam ser diferentes do que realmente são". A imaginação é entendida por Arendt como a capacidade de fazer presente o ausente: quando o objeto está muito próximo, imediato, a imaginação dá o distanciamento necessário para eliminar eventuais prejuízos e parcialidades; quando o objeto está distante, ela o torna 
familiar. Além disso, também, imaginar, como nos lembra Ricoeur (2000, p. 138), significa não apenas representar uma coisa ausente, mas também pôr-se no lugar de um outro ser humano próximo ou distante. A imaginação, em termos arendtianos, é uma capacidade humana de fundamental importância; é a única bússola interior que possuímos, sem ela não seremos capazes de nos orientarmos no mundo, pois "somente a imaginação nos permite ver as coisas em suas perspectivas próprias". Ou seja, somente a imaginação é capaz de colocar "a uma certa distância o que está próximo demais para que possamos ver e compreender sem tendências ou preconceitos"; e somente ela permite também "superar os abismos que nos separam do que é remoto, para que possamos ver e compreender tudo o que está longe demais como se fosse assunto nosso" (ARENDT, 1993, p. 53).

A postura de Arendt diante do inédito, isto é, diante do fenômeno totalitário, ou em outros termos, o método utilizado por ela para compreender os regimes totalitários possibilitou a ela não apenas desvendar uma forma de dominação singular e sem precedentes tornada possível, principalmente, pelo aparecimento do homem massa, mas também demonstrar a possibilidade do mal radical até então absolutamente inconcebível pela nossa tradição de pensamento. Portanto, diante dos regimes totalitários, em termos arendtianos, significa estar na presença de sistema político inédito, nunca existiu nada que lhe fosse semelhante. Portanto, em vão se procurarão os traços ou as premissas em experiências anteriores, a não ser que se caia em generalidades e redundâncias: crueldade, despotismo, tirania, ditadura, etc. É verdade, por exemplo, que houve muitas tiranias sangrentas antes do século XX, como nos lembra Fukuyma (1992, p. 32); não é menos verdade, também, que a tirania diocleciana ou a dos shoguns no Japão acentuaram de maneira especial a aquiescência da população ao controle centralizado, ambos os sistemas, como nos lembra Brzezinski (1963, p. 16), implantaram uma atmosfera de medo, através de um sistema de informação de polícia secreta; a própria história humana é uma estrada jurada de cadáveres e de aspiração ao controle total, de alguns tentando desesperadamente impor a qualquer custo as suas ideias para dominar integralmente as vontades alheias, matando, mentindo e oprimindo, mas ninguém tornou-se tão integralmente totalitário e cruel em seu domínio quanto Hitler com o seu "raciocínio frio como gelo", e Stalin com a "impiedade da sua dialética"(Arendt, 1990, p. 524). Tanto o comunismo como o nazismo, como obervou Besançon (2000, p. 9), se achavam no dever de realizar todas as suas ideias, não importa se têm de matar, aliás, para eles, o objetivo era "chegar a uma sociedade perfeita, destruindo os elementos negativos que se opõem a ela... ambos se dão o direito - e mesmo o dever - de matar". 


\section{III}

O totalitarismo é, sem dúvida, uma forma de governo que desafia absolutamente qualquer tipo de expressão mais antiga utilizada por Aristóteles ou Montesquieu para conceitualizar as formas de governo ao longo da história. $\mathrm{O}$ totalitarismo parece a palavra que Tocqueville (1977, p. 531) estava procurando quando em uma das suas passagens proféticas disse que "os povos democráticos se acham ameaçados" por uma opressão cujo sentido é difícil de se reproduzir, pois “o fenômeno é novo; é preciso, pois, defini-lo, já que não posso dar-lhe um nome". O totalitarismo não é tirania nem despotismo. Na verdade, como disse Friedrich e Brzezinski (1965, p. 16-20), identificar tal fenômeno com os despotismos ocidentais do passado mais remoto, com as monarquias absolutas da Europa da era moderna, com as tiranias das antigas cidades gregas, com o Império Romano, com a tirania das cidadesestados da Renascença italiana ou com as ditaduras militares bonapartistas é, certamente, elogiá-lo. Se o totalitarismo pudesse ser realmente identificado com esses tipos de males do passado, estaríamos pisando "em terra firme", diz Arendt (1993, p. 41), "pois cremos ter herdado, junto com os males do passado, a sua sabedoria para nos orientar em meio a eles". Ao longo dos tempos, como nos lembra Arendt (1990, p. 513), as tiranias foram caracterizadas de dois modos: de um lado, como "o poder arbitrário, sem freio das leis, exercido no interesse do governante e contra os interesses dos governados" e de outro lado, como "o medo que o povo tem pelo governante e o medo do governante pelo povo.

Nessas tiranias o indivíduo tinha a liberdade de pelo menos escolher a oposição, uma liberdade limitada, pois sabia que corria o risco de ser torturada ou morta; porém, uma liberdade recusada à vítima do sistema totalitário. O totalitarismo só se contenta quando eliminar não apenas a liberdade em todo sentido específico, mas a própria fonte da liberdade que, segundo Arendt, está no nascimento do homem e na sua capacidade de começar de novo. No mundo totalitário realizar um ato voluntário nada mais é do que a garantia de um castigo máximo que qualquer outro poderia sofrer de qualquer modo. Sob esse regime político, portanto, a pessoa já nem pode salvar-se através de uma morte dotada de sentido praticando um ato heroico, pois qualquer morte pode se dissolver no meio das incontáveis mortes arbitrárias de pessoas que nada fizeram contra a lei totalitária.

O totalitarismo: que, segundo F. Sheen (1961, p. 22), exige “o domínio total do homem - do homem todo, corpo e alma" e visa "o controle dos mais recônditos setores do espírito"; que D. Bell (1980, p. 260) caracterizou como uma "eliminação de todas as 
instituições intermediárias, entre as 'massas' e líder"; uma forma de governo que "não tolera oposição", nas palavras de A. Brecht (1965, p. 566); "a maior desgraça que, no século XX atingiu o continente europeu", segundo A. Touraine (1996, p. 10); "o único tipo distintamente moderno de governo", na opinião de B. Crick (1981, p. 4), ou ainda, de acordo com G. Sartori (1994, p. 261), “um nome novo para algo até então sem nome". Tal totalitarismo surge definitivamente como uma forma de governo inclassificável dentro dos moldes da filosofia política (ARENDT, 1990, p. 339-340).

Semelhante forma de governo, portanto, como entendido por Arendt (1990, p. 513), eliminou por completo "a própria alternativa sobre a qual se baseiam, na filosofia política, todas as definições da essência dos governos, isto é, a alternativa entre o governo legal e o ilegal, entre o poder arbitrário e o poder legítimo". Em sua ação total, ele se liberta de tudo aquilo que é capaz de oferecer-lhe resistência. Em relação à lei, por exemplo, o totalitarismo se coloca acima de qualquer objetividade e estabilidade da lei positiva ao afirmar "obedecer rigorosa e inequivocamente àquelas leis da Natureza ou da História que sempre acreditamos serem a origem de todas as leis" (ARENDT, 1990, p. 513). Na verdade, ele substitui o estado de direito pela lei de movimento perpétuo, pela lei "verdadeira", pela lei "absoluta", pela lei que "incontestavelmente" lhe dá o "direito de matar" em nome de um domínio total, e cada uma das suas iniciativas pretende inscrever-se única e exclusivamente nessas leis preexistentes: as leis biológicas da natureza, ou as leis sociais da História. Assim, o Führer tem por missão interpretar as leis da Natureza e deduzir o que é bom e são para o povo alemão; Stalin está encarregado da interpretação das leis da História, a partir das quais elabora máximas da ação imediatamente aplicáveis à sociedade soviética e ao movimento comunista internacional, e é da lei da Natureza e da História eliminar tudo o que é prejudicial ou incapaz de viver. Mesmo pelo absurdo, o totalitarismo manifesta uma das dimensões essenciais do direito: o direito é uma resposta à necessidade humana fundamental de estabilidade.

Os regimes totalitários se libertam também da própria realidade através da ideologia. Essa "lógica de uma ideia" que no fundo é a expressão da vontade do chefe despreza totalmente os fatos e as opiniões. Elimina-os totalmente, mesmo que esses fatos ou opiniões representem milhões de indivíduos. Sob os regimes totalitários a ideologia é o instrumento essencial para explicar absolutamente e de maneira total o curso da história: "os segredos do passado, as complexidades do presente, as incertezas do futuro" (ARENDT, 1990, p. 521). Por um lado, a ideologia forma um sistema de interpretação definitiva do mundo, por outro lado, afirma desde logo o seu caráter irrecusável, infalsificável. Ela é mobilizada para que 
ninguém jamais comece a pensar, ou pelo menos, como disse Bauman (2000, p. 94), para tornar o pensamento dos indivíduos "impotente, irrelevante e sem influência para o sucesso ou fracasso do poder”. Ela arruína todas as relações com a realidade e constrói um mundo fictício e logicamente coerente. Por último, o totalitarismo liberta-se da pluralidade, ao exigir a unanimidade e não tolerar nenhum tipo de debate de opiniões. Nada além de obedecer rigorosamente e incondicionalmente às ordens do chefe. Afinal, debater para quê, se tudo está "explicado" e "esclarecido". Todas essas "libertações são tornadas possíveis graças ao terror implacável”. Por isso, nas palavras de Arendt (1990, p. 526), o totalitarismo é definido como "uma forma de governo cuja essência é o terror e cujo princípio de ação é a lógica do pensamento ideológico"; uma mistura nunca antes usada nas várias formas de domínio político.

Ora, se tudo o que se falou anteriormente fosse simplesmente um delírio de Hitler e de Stalin, ou permanecesse apenas como uma teoria, talvez a história da humanidade não seria manchada por essa barbárie. Todavia, infelizmente, para Hitler e Stalin, não existem limites entre pensar ou desejar e fazer. Ou seja, para eles, "tudo é possível”. Se ao nível do pensamento ou da vontade um governo total e seguro é "real", significa, também, que ele é "possível e real" na prática. Basta utilizar o terror total para que o mundo dos homens se transforme em um espelho fiel das premissas ideológicas dos governos totalitários. Em todos os lugares "das fronteiras e dos canais de comunicação entre os homens individuais", diz Arendt (1990, p. 518), os regimes totalitários construíram "um cinturão de ferro que os cinge de tal forma", dissolvendo suas pluralidades “em Um-Só-Homem de dimensões gigantesca", pressionando-os uns contra os outros. Para garantir a propagação e aceitação absoluta da sua lógica como única explicação e a única verdade, e ter a certeza de que ninguém possa contrariá-la, o totalitarismo não se contenta simplesmente em isolar os homens, ou seja, colocá-los numa situação, onde por definição, de acordo com a compreensão arendtiana, eles não podem agir, não podem se revelar; ele "fabrica um novo homem", um "Homem único" capaz de se adequar absolutamente e incondicionalmente aos moldes do regime através de uma obediência cega.

\section{REFERÊNCIAS}

ARENDT, H. Origens do totalitarismo. Trad. Roberto Raposo. São Paulo: Companhia das Letras, 1990.

ARENDT, H. Compreender: formação, exílio e totalitarismo. Trad. Denise Bottmann. São Paulo: Companhia das Letras; Belo Horizonte: Editora UFMG, 2008. 
ARENDT, H. A dignidade da política. Trad. Antônio Abranches et ali. Rio de Janeiro: Relume Dumará, 1993.

ARENDT, H. Entre o passado e o futuro. Trad. Mauro Barbosa de Almeida. São Paulo: Perspectiva, 1988.

ARENDT, H. O que é política? Trad. Reinaldo Guarany. Rio de Janeiro: Bertrand Brasil, 1999.

ARENDT, H. Crises da república. Trad. José Valkmann. São Paulo: Perspectiva, 1973.

BAUMAN, Zygmunt. Em busca da política. Trad. Marcus Penchel. Rio de Janeiro: Zahar, 2000.

BELL, Dniel. O fim da ideologia. Trad. Sérgio Bath. Brasília: UnB, 1980.

BESANÇON Alain. A infelicidade do século: sobre o comunismo, o nazismo e a unidade da shoah. Trad. Emir Sader. Rio de Janeiro: Bertrand Brasil, 2000.

BRECHT, Arnord. Teoria política: fundamentos do pensamento político do século XX. Trad. Álvaro Cabral. Rio de Janeiro: Zahar, 1965.

BRZEZINSKI, Zbgniew. Ideologia e poder na política soviética. Trad. Gilda Costa. Rio de Janeiro: GRD, 1963.

DUARTE, André. O pensamento à sombra da ruptura: política e filosofia em Hannah Arendt. São Paulo: Paz e Terra, 2000.

FRIEDRICK, Carl. Tradição e autoridade em ciência política. Trad. Fernando Ferro. Rio de Janeiro: Zahar, 1974.

FRIEDRICK, Carl \& BZEZINSKI, Zbigniew. Totalitarismo e autocracia. Trad. Donaldson Garschagen. Rio de Janeiro: GRD, 1965.

FUKUYAMA, Francis. O fim da história e o último homem. Trad. Auly Rodrigues. Rio de Janeiro: Rocco, 1992.

RICOEUR, Paul. Juízo estético e juízo político segundo Hannah Arendt. In: O justo ou a essência da justiça. Trad. Vasco Casimiro. Lisboa: Piaget, 2000.

ROVIELLO, Anne-Marie. Senso comum e modernidade em Hannah Arendt. Trad. Benedicte Hovart e João Felipe Marques. Lisboa: Piaget, 1990.

SARTORI, Giovanni. A teoria da democracia revisitada. Trad. Dinah Azevedo. São Paulo: Ática, 1994.

SHEEN, Fulton. Filosofia em luta. Trad. Cypriano Costa. Rio de Janeiro: Agir,1961. 
TOCQUEVILLE, Alex. A democracia na América. Trad. Neil Ribeiro. São Paulo: Editora da Universidade de São Paulo, 1977.

TOURAINE, Alain. Crítica da modernidade. Trad. Elias Ferreira Edel. Rio de Janeiro: Vozes, 1994.

YOUNG-BRUEHL, Elisabeth. Hannah Arendt: por amor ao mundo. Trad. Antônio Trânsito. Rio de Janeiro: Relume Dumará, 1997. 